\title{
Uwarunkowania sympatii wobec PJN i RP w badaniach postaw politycznych studentów
}

\author{
KEY WORDS \\ political attitudes, \\ students, Poland \\ Comes First, \\ Palikot's Movement \\ (Your Movement), \\ Paweł Kowal, \\ Janusz Palikot
}

\begin{abstract}
Pawełczyk Piotr, Jankowiak Barbara, Gulczyńska Anna, Uwarunkowania sympatii wobec PJN i RP w badaniach postaw politycznych studentów [Conditioning of Appreciation Towards PJN and RP in Studies of Students' Political Attitudes]. Kultura - Społeczeństwo - Edukacja nr 2 (4) 2013, Poznań 2013, pp. 129-140, Adam Mickiewicz University Press. ISBN 978-83-232-2708-3. ISSN 2300-0422
\end{abstract}

The aim of the following work is to analysis the results of survey concerning the structures and conditioning of students' political attitudes. The factors which create appreciation to two political parties, Palikot's Movement (presently Your Movement) and Poland Comes First and their leaders, were shown. The assessment of sympathy towards the parties was made in order to find out if it is not related with the political organizations from which the leaders come (Civic Platform and Law and Justice). The issue of emotions was also analysed since they are important elements of the attitudes, as well as they form them. The studies associated with the political attitudes improve that emotions towards the candidates have an impact on the voting process. Electors often have preconception feelings towards the candidates when they don't know anything about their platforms. The survey shows, that Janusz Palikot is much more recognizable as the politician than Paweł Kowal. The attitudes towards his party are very emphatic and they are related with the antipathy to Law and Justice and Jarosław Kaczyński and with the sympathy to Donald Tusk, the prime minister. The analysis also suggest that the supporters of Poland Comes First create their views through the traditional socializing agendas like the social background, whereas the supporters of Janusz Palikot's party form their views on the basis of contact with their partners, at the same time rejecting the traditional socializing institution as the church. 


\section{Wprowadzenie}

Schyłek pierwszej kadencji rządów koalicji PO i PSL zaowocował zmianami na polskiej scenie politycznej. Pojawiły się ugrupowania liczące na zagospodarowanie znacznej części elektoratu rozczarowanego zarówno rządami koalicji, jak i polityką opozycyjną PiS. W 2010 roku powstało ugrupowanie Polska Jest Najważniejsza, w którym znaleźli się liderzy niewidzący swojej przyszłości w Prawie i Sprawiedliwości, między innymi Joanna Kluzik-Rostkowska, Elżbieta Jakubiak, Paweł Kowal, Paweł Poncyliusz, Marek Migalski'. Spośród parlamentarzystów Platformy Obywatelskiej szans na nowe rozdanie w wyborach parlamentarnych upatrywał Janusz Palikot, dystansując się coraz bardziej od swojej partii i tworząc najpierw stowarzyszenie Ruch Poparcia Palikota, a następnie przekształcając go w partię politycznąㄹ. 6 października 2013 roku na bazie Ruchu Palikota, środowisk Ruchu Społecznego Europa Plus, a także członków innych partii lewicowych powstała polska centrolewicowa partia polityczna Twój Ruch ${ }^{3}$.

Nowy byt polityczny, jakim był Ruch Palikota, miał być alternatywą liberalno-światopoglądową dla Platformy Obywatelskiej. Powstanie PJN było raczej wynikiem rozczarowania kilku polityków PiS - będących twarzami kampanii wyborczej Jarosława Kaczyńskiego - obwinianiem ich za niepowodzenia kampanii, niż próbą stworzenia alternatywy programowej.

Celem niniejszej pracy jest analiza uwarunkowań postaw emocjonalnych wobec PJN i RP oraz sprawdzenie, czy są one niezależne od postaw wobec ugrupowań, z których wywodzą się liderzy owych bytów politycznych - PO i PiS ${ }^{4}$. Wydaje się to być istotne w kontekście szans obu ugrupowań na sukces wyborczy w kolejnych wyborach parlamentarnych.

Przyjmuje się, że postawa to generalnie pozytywne lub negatywne nastawienie wobec kogoś lub czegoś znajdujące odzwierciedlanie w przekonaniach, emocjach oraz zamierzonych zachowaniach (Myers, 2003: 152). Trójskładnikowa definicja postawy mówi, iż tworzą ją komponenty:

- poznawczy - który dotyczy myśli i przekonań ludzi o przedmiocie postawy (a więc $\mathrm{w}$ przypadku postaw politycznych o polityce, systemie politycznym

\footnotetext{
${ }^{1}$ http://www.polityka.pl/kraj/1514288,1,pjn-partia-sad-zarejestrowal-statut.read?backTo=http://www.polityka.pl/kraj/analizy/1515882,1,jak-nie-powstaje-pjn.read

${ }^{2}$ http://wiadomosci.dziennik.pl/polityka/artykuly/303891,palikot-odchodzi-z-po-z-sejmu-izaklada-partie.html

${ }^{3}$ http://polska.newsweek.pl/palikot-twoj-ruch-to-nowa-nazwa-parti-na-newsweek-pl,artykuly,271980,1.html

${ }^{4}$ Wyniki, które posłużą do dokonania analiz, stanowią część szerszego projektu badawczego „Diagnoza postaw politycznych studentów poznańskich uczelni” realizowanego w WSNHID pod kierownictwem dr Karoliny Churskiej-Nowak.
} 
jako o całości, instytucjach politycznych, partiach politycznych, ich kandydatach, programach);

- afektywny (emocjonalny) - dotyczy reakcji emocjonalnych przejawianych wobec przedmiotu postawy, którymi w przypadku postaw politycznych są: polityka, system polityczny, instytucje polityczne, politycy;

- behawioralny - dotyczy działań jednostki, a więc jest to dające się zaobserwować zachowanie wobec przedmiotu postawy (tj. aktywność polityczna: konwencjonalna i niekonwencjonalna, partycypacja polityczna, zachowania wyborcze) (Aronson, Wilson, Akert, 1997: 314).

Przedstawiona $\mathrm{w}$ pracy analiza dotyczyć będzie emocjonalnego komponentu postaw politycznych, ponieważ istnieje wiele badań wskazujących na znaczącą rolę emocji wobec polityków w podejmowaniu decyzji wyborczych. Joanna Mandrosz, opisując czynniki ograniczające racjonalność poglądów i zachowań politycznych (Mandrosz, 2002: 177), cytuje wyniki badań przeprowadzonych przez Abelsona, Kindera, Petersa i Fiske (1982) w czasie prezydenckiej kampanii w USA w 1980 roku. Wynika z nich, że ogólną ocenę kandydata na prezydenta można przewidzieć na podstawie emocji, jakie dany polityk wzbudza wśród wyborców. Sądy poznawcze, które w opisywanym badaniu określane były jako pewne cechy przypisywane kandydatom, na przykład „uczciwość”, lub opisy behawioralne, takie jak na przykład „mógłby rozwinąć dobre stosunki z innymi państwami” okazały się wywierać znacznie mniejszy wpływ na preferencje wyborcze niż emocje odczuwane do kandydatów ${ }^{5}$.

$\mathrm{W}$ niniejszej pracy analizie poddano uwarunkowania emocjonalnego komponentu postaw politycznych wśród studentów pierwszego roku kierunków społecznych. Badania najmłodszych generacji wykazują spadek zainteresowania i zaangażowania oraz cynizm polityczny (Smith, 1999: 553-580; Delli Caprini, 2000: 341-349). Ponieważ jednym $\mathrm{z}$ istotnym mierników politycznego zaangażowania we współczesnych demokracjach jest udział w wyborach, warto przywołać opisywaną w literaturze tendencję, zgodnie, $\mathrm{z}$ którą wiek jest istotnym czynnikiem społeczno-demograficznym determinującym uczestnictwo. Mimo że młodsze grupy wiekowe są lepiej wykształcone niż starsze, mają słabszy poziom wiedzy o polityce, niższą partycypację w organizacjach politycznych i niższy udział w wyborach (Uslaner, 1998: 441-467). W wielu krajach utrzymuje się duży procent niegłosujących wśród młodych ludzi (Franklin, 1996).

Celem badań jest dokonanie analizy postaw politycznych studentów poznańskich uczelni oraz włączenie się w dyskusję dotyczącą stopnia zainteresowania młodzieży polityką.

${ }^{5}$ Korespondujące $\mathrm{z}$ opisywanymi wynikami dane uzyskano i opisano w pracy: P. Pawełczyk, B. Jankowiak, (2013). Cechy wizerunku politycznego a emocje w głosowaniu na Bronisława Komorowskiego i Jarosława Kaczyńskiego w wyborach prezydenckich $w 2010$ roku. Raport z badań postaw politycznych studentów. „Przegląd Politologiczny” Rok XVII, nr 2, s. 35-45. 


\section{Metodologia badań własnych}

1. Cele badań

a) Zbadanie postaw politycznych studentów (w tej części analizy komponentu afektywnego).

b) Zbadanie struktury postaw politycznych studentów.

c) Zbadanie uwarunkowań postaw politycznych studentów.

W prezentowanym artykule zostaną przedstawione wyniki badań dotyczące struktury i uwarunkowań afektywnego komponentu postaw politycznych.

2. Charakterystyka osób badanych

Wybór osób do badań był doborem celowym. Do grupy badanej zostali wybrani studenci pierwszego roku studiów. Analizie poddano postawy polityczne w jednej ze specyficznych subkultur, jaką stanowi kultura polityczna młodzieży studenckiej (Garlicki, Bogomilski, 2004).

Tabela 1. Charakterystyka osób badanych

\begin{tabular}{|c|c|}
\hline $\begin{array}{c}\text { Zmienne } \\
\text { socjodemograficzne }\end{array}$ & Dane liczbowe \\
\hline 1 & 2 \\
\hline Liczebność & 573 osoby \\
\hline Płeć & $\begin{array}{l}\text { Kobiety } 424(74 \%) \\
\text { Mężczyźni } 138(24,1 \%)\end{array}$ \\
\hline Miejsce pochodzenia & $\begin{array}{l}\text { Wieś } 157(27,40 \%) \\
\text { Miasto do } 50 \text { tys. mieszkańców } 175 \text { (30,54\%) } \\
\text { Miasto powyżej } 50 \text { tys. do } 200 \text { tys. mieszkańców } 102(17,80 \%) \\
\text { Miasto powyżej } 200 \text { tys. do } 500 \text { tys. mieszkańców } 42(7,33 \%) \\
\text { Miasto powyżej } 500 \text { tys. mieszkańców } 92(16,06 \%)\end{array}$ \\
\hline Religijność & $\begin{array}{l}\text { Głęboko wierzący/a } 62(10,82 \%) \\
\text { Wierzący/a } 306(53,40 \%) \\
\text { Poszukujący/a religijnie } 80(13,96 \%) \\
\text { Niewierzacy/a } 79(13,79 \%) \\
\text { Inny } 36(6,28 \%)\end{array}$ \\
\hline Kierunek studiów & $\begin{array}{l}\text { Pedagogika } 189(32,98 \%) \\
\text { Psychologia } 75(13,09 \%) \\
\text { Politologia } 67(11,69 \%) \\
\text { Stosunki międzynarodowe } 93(16,23 \%) \\
\text { Bezpieczeństwo narodowe } 33(5,76 \%) \\
\text { Dziennikarstwo i komunikacja społeczna } 107(18,67 \%)\end{array}$ \\
\hline Wykształcenie matki & $\begin{array}{l}\text { Podstawowe } 9(1,57 \%) \\
\text { Zasadnicze zawodowe } 70(12,22 \%) \\
\text { Średnie zawodowe } 115(20,07 \%) \\
\text { Średnie ogólne } 69(12,04 \%) \\
\text { Policealne / pomaturalne } 42(7,33 \%) \\
\text { Niepełne wyższe } 24(4,19 \%) \\
\text { Wyższe } 239(41,71 \%)\end{array}$ \\
\hline
\end{tabular}




\begin{tabular}{|l|l|}
\hline 1 & \\
\hline Wykształcenie ojca & Podstawowe 13 $(2,27 \%)$ \\
& Zasadnicze zawodowe 120 (20,94\%) \\
& Średnie zawodowe 144 (25,13\%) \\
& Średnie ogólne 61 (10,65\%) \\
& Policealne / pomaturalne 40 (6,98\%) \\
& Niepełne wyższe 30 (5,24\%) \\
& Wyższe 154 (26, 88\%) \\
\hline
\end{tabular}

\section{Metoda badawcza}

W badaniach zastosowano metody analizy statystycznej, technikę ankiety, poprzez zastosowanie narzędzia badawczego specjalnie skonstruowanego do celów badań „Kwestionariusza do badania postaw politycznych studentów”. Wykorzystuje ono wiedzę z zakresu psychologii społecznej, psychologii politycznej, politologii oraz metodologii badań. Cennymi w konstrukcji skal zaangażowania politycznego, oceny postawy obywatelskiej oraz skali patriotyzm-nacjonalizm były badania przygotowanie przez Instytut Dziennikarstwa Uniwersytetu Warszawskiego (Jakubowski, Marciniak, Załęski, 2008).

W przypadku zastosowanych skal obliczono ich rzetelność. Uzyskano wysoką rzetelność skal (wyniki przedstawiono poniżej). Kwestionariusz składał się z ośmiu części:

I - metryczkowej;

II - dotyczącej komponentu poznawczego postaw politycznych (dyferencjały semantyczne dotyczące cech wizerunku politycznego);

III - dotyczącej komponentu emocjonalnego postaw politycznych (nasilenie emocji pozytywnych i negatywnych wobec polityków, partii politycznych, instytucji politycznych);

IV - dotyczącej komponentu behawioralnego postaw politycznych (partycypacja polityczna);

$\mathrm{V}$ - dotyczącej oceny wpływu agend socjalizujących na sympatie polityczne oraz korzystania z mediów zarówno nowych jak i tradycyjnych;

VI - skali zaangażowania politycznego, rzetelność skali AlphaCronbacha wynosi 0,839;

VII - skali oceny postawy obywatelskiej, rzetelność skali AlphaCronbacha wynosi 0,77 ;

VIII - skali patriotyzm-nacjonalizm, rzetelność skali AlphaCronbacha wynosi 0,769 .

Dołączono także dwie dodatkowe skale:

PWI - Psychospołeczne prosperowanie, rzetelność skali AlphaCronbacha wynosi 0,86 ; 
SP - Wskaźnik Osobistego Dobrostanu, rzetelność skali AlphaCronbacha wynosi 0,84 .

4. Organizacja badań

a) Etap selekcyjny - wybór osób do badań.

b) Etap badań właściwych - anonimowe badania kwestionariuszowe.

c) Etap opracowania wyników w programie SPSS oraz ich interpretacji.

\section{Wyniki badań}

Struktura emocjonalnych komponentów postaw wobec polityki

Emocjonalny komponent postawy badano, prosząc studentów o zaznaczenie na skali od 0 do 10 nasilenia emocji pozytywnych i negatywnych wobec polityków i partii politycznych. W przypadku polityków możliwe było także zaznaczenie opcji „nie znam tego polityka”.

Przeprowadzono analizę głównych składowych odnośnie emocjonalnych komponentów postaw wobec wyróżnionych osób i struktur. Celem było określenie zależności wyższego rzędu pomiędzy jednostkowymi postawami (politykami, partiami politycznymi, instytucjami politycznymi, polityką). Uzyskane wyniki zaprezentowano w tabeli 2 .

Tabela 2. Struktura postaw emocjonalnych studentów (macierz rotowanych składowych)

\begin{tabular}{|l|c|c|c|c|c|}
\hline \multirow{2}{*}{$\begin{array}{c}\text { Emocjonalne } \\
\text { komponenty } \\
\text { postaw }\end{array}$} & $\begin{array}{c}\text { Sympatia } \\
\text { wobec PO } \\
\text { i rządu oraz } \\
\text { antypatia } \\
\text { wobec PiS }\end{array}$ & $\begin{array}{c}\text { Sympatia } \\
\text { wobec } \\
\text { RP oraz } \\
\text { antypatia } \\
\text { wobec PiS }\end{array}$ & $\begin{array}{c}\text { Pozytywne } \\
\text { emocje } \\
\text { wobec } \\
\text { polityki }\end{array}$ & $\begin{array}{c}\text { Sympatia } \\
\text { wobec SLD }\end{array}$ & $\begin{array}{c}\text { Sympatia } \\
\text { wobec PJN }\end{array}$ \\
\hline \multicolumn{1}{|c|}{1} & 2 & 3 & 4 & 5 & 6 \\
\hline Rząd &, 783 & - & - & - & - \\
\hline PO &, 773 & - & - & - & - \\
\hline D. Tusk &, 754 &, 421 & - & - & - \\
\hline B. Komorowski &, 747 & - & - & - & - \\
\hline Senat &, 665 & - & - & - & - \\
\hline UE &, 595 & - & - & - & - \\
\hline J. Palikot & - &, 890 & - & - & - \\
\hline Ruch Palikota & - &, 867 & - & - & - \\
\hline J. Kaczýnski &,- 467 &,- 506 & - & - & - \\
\hline
\end{tabular}




\begin{tabular}{|l|c|c|c|c|c|}
\hline \multicolumn{1}{|c|}{1} & 2 & 3 & 4 & 5 & 6 \\
\hline PiS &,- 460 &,- 501 & - & - & - \\
\hline polityka & - & - &, 790 & - & - \\
\hline partie polityczne & - & - &, 770 & - & - \\
\hline Sejm &, 483 & - &, 567 & - & - \\
\hline SLD & - & - & - &, 826 & - \\
\hline G. Napieralski & - & - & - &, 824 & - \\
\hline P. Kowal & - & - & - & - &, 889 \\
\hline PJN & - & - & - & - &, 849 \\
\hline
\end{tabular}

Analiza głównych składowych w odniesieniu do PJN wskazuje, że postawy emocjonalne wobec tej partii są niezależne od pozostałych postaw - wiążą się wyłącznie z sympatią wobec jej lidera - nie wiążą się z sympatią wobec PiS.

Jako bardziej znaczące wyodrębniły się postawy emocjonalne wobec Ruchu Palikota. W badanej grupie pozytywne odniesienia emocjonalne wobec tej partii są silnie związane $\mathrm{z}$ antypatią wobec PiS. Jednocześnie sympatia wobec Ruchu Palikota nie wiąże się z sympatią wobec Platformy Obywatelskiej, ale wiąże się z sympatią wobec premiera Donalda Tuska. Jednocześnie warto zauważyć, że sympatycy PO nie darzą Janusza Palikota pozytywnymi emocjami. Mogłoby to wskazywać na popularność Donalda Tuska wśród młodych, wykształconych wyborców oraz jego potencjalne możliwości odebrania tego elektoratu Januszowi Palikotowi. Postawy emocjonalne wobec PO i RP są podobne pod względem silnego związku z antypatią wobec PiSu i Jarosława Kaczyńskiego. Można więc przypuszczać, że dla wyborców tych partii istotne znaczenie w podejmowaniu decyzji wyborczych ma lęk przed powrotem PiS do władzy.

Analiza pozostałych składowych wykracza poza temat niniejszej pracy i została omówiona w odrębnym opracowaniu (Pawełczyk, Churska-Nowak, Jankowiak, 2012).

Następnie zastosowano analizę regresji metodą krokową w celu sprawdzenia zależności pomiędzy nasileniem emocji wobec partii politycznych i polityków a:

- wybranymi zmiennymi socjodemograficznymi (płeć, stan cywilny, miejsce pochodzenia, religijność, ocena sytuacji materialnej, wykształcenie rodziców);

- opracowanymi i zastosowanymi skalami;

- subiektywną oceną wpływu podmiotów socjalizujących (rodzina pochodzenia, religia, szkoła/uczelnia, media, znajomi, partner/małżonek).

Analiza uzyskanych w ten sposób wyników umożliwia ocenę uwarunkowań postaw emocjonalnych badanych. 
Uwarunkowania postaw emocjonalnych wobec Ruchu Palikota oraz Janusza Palikota

W tabeli 3 przedstawiono czynniki warunkujące sympatię wobec Ruchu Palikota, a w tabeli 4 czynniki warunkujące sympatię wobec lidera tej partii.

Tabela 3. Uwarunkowania emocjonalnego komponentu postaw politycznych wobec RP

\begin{tabular}{|l|c|c|c|}
\hline \multicolumn{1}{|c|}{ Uwarunkowania postaw } & $\begin{array}{c}\text { Współczynnik } \\
\text { standaryzowany } \\
\text { Beta }\end{array}$ & $\mathbf{T}$ & Istotność \\
\hline Religijność &,- 255 & $-4,952$ &, 000 \\
\hline Wpływ organizacji religijnej &,- 234 & $-4,672$ &, 000 \\
\hline Skala patriotyzm-nacjonalizm &,- 130 & $-2,535$ &, 012 \\
\hline Wpływ partnera &, 107 & 2,215 &, 027 \\
\hline
\end{tabular}

Analiza wyników badań wskazuje istnienie czterech zmiennych warunkujących pozytywne postawy emocjonalne wobec RP. Osoby przejawiające sympatie wobec Ruchu Palikota cechuje przede wszystkim niski poziom religijności oraz przekonanie, że na ich postawy nie ma wpływu żadna organizacja religijna. Osoby przejawiające sympatię wobec Ruchu Palikota cechuje niski poziom nacjonalizmu. Sympatycy tej partii jako znaczący podmiot socjalizacji politycznej wskazują osobę, z którą tworzą relację intymną. Może to sygnalizować znaczące dla funkcjonowania ich związku partnerskiego wspólne poglądy społeczno-polityczne oraz małe znaczenie w kształtowaniu preferencji wyborczych wśród tej grupy tradycyjnych agend socjalizacji politycznej.

Zanim badani studenci proszeni byli o określenie na skali swojego nastawienia emocjonalnego wobec Janusza Palikota, konieczne było ustalenie, czy znają tego polityka. $96,68 \%$ (554 osoby) badanych odpowiedziało twierdząco na to pytanie.

Tabela 4. Uwarunkowania emocjonalnego komponentu postaw politycznych wobec Janusza Palikota

\begin{tabular}{|l|c|c|c|}
\hline \multicolumn{1}{|c|}{ Uwarunkowania postaw } & $\begin{array}{c}\text { Współczynnik } \\
\text { standaryzowany } \\
\text { Beta }\end{array}$ & $\mathbf{T}$ & Istotność \\
\hline Religijność &,- 256 & $-4,995$ &, 000 \\
\hline Wpływ organizacji religijnej &,- 240 & $-4,948$ &, 000 \\
\hline Skala patriotyzm-nacjonalizm &,- 135 & $-2,621$ &, 009 \\
\hline
\end{tabular}


Wyniki przeprowadzonych badań wskazują, że uwarunkowania sympatii wobec Janusza Palikota to niska religijność, przekonanie o niezależności własnych poglądów politycznych od organizacji religijnych oraz niski poziom nacjonalizmu. Należy zwrócić uwagę, że wszystkie trzy determinanty sympatii wobec tego polityka są negatywne, co może wskazywać, że postawa ta oparta jest bardziej na negacji określonych poglądów niż afirmacji.

Uwarunkowania postaw emocjonalnych wobec PJN oraz Pawła Kowala

Czynniki warunkujące sympatię wobec PJN oraz jej lidera przedstawiono w tabeli 5 i 6 . Przed określeniem na skali swojego nastawienia emocjonalnego wobec Pawła Kowala studenci pytani byli, czy znają tego polityka. Zaledwie 34,21\% (196 osób) badanych odpowiedziało twierdząco na to pytanie.

Tabela 5. Uwarunkowania emocjonalnego komponentu postaw politycznych wobec PJN

\begin{tabular}{|l|c|c|c|}
\hline Uwarunkowania postaw & $\begin{array}{c}\text { Współczynnik } \\
\text { standaryzowany } \\
\text { Beta }\end{array}$ & $\mathbf{T}$ & Istotność \\
\hline Wpływ rodziny &, 255 & 4,507 &, 000 \\
\hline
\end{tabular}

Tabela 6. Uwarunkowania emocjonalnego komponentu postaw politycznych wobec Pawła Kowala

\begin{tabular}{|c|c|c|c|}
\hline Uwarunkowania postaw & $\begin{array}{c}\text { Współczynnik } \\
\text { standaryzowany } \\
\text { Beta }\end{array}$ & $\mathbf{T}$ & Istotność \\
\hline Skala patriotyzm-nacjonalizm &, 193 & 2,285 &, 024 \\
\hline
\end{tabular}

Analiza wyników badań wykazała istnienie tylko jednego czynnika warunkującego sympatię wobec PJN i jednego warunkującego sympatię wobec jego lidera. W przypadku partii politycznej jest to przekonanie o wpływie rodziny na własne postawy polityczne badanych. Znaczenie tej tradycyjnej agendy socjalizacji politycznej w kształtowaniu postaw wobec analizowanej organizacji politycznej nie jest zaskakujące w obliczu prorodzinnych postulatów tej partii. W przypadku Pawła Kowala jedynym czynnikiem warunkującym sympatię do tego polityka jest wysoki wynik w skali patriotyzm-nacjonalizm. 


\section{Wnioski}

Przeprowadzone badania i ich wyniki pozwalają wysnuć kilka wniosków:

1. Istnieją znaczące różnice w rozpoznawalności liderów RP i PJN. Janusza Palikota zna zdecydowana większość badanych studentów (96,68\%) natomiast Pawła Kowala zaledwie jedna trzecia badanych $(34,21 \%)$. Wskazuje to na skuteczność prowadzonej kampanii w odniesieniu do grupy młodych wykształconych wyborców.

2. Już ze względu na rozpoznawalność liderów nie jest zaskakujące, że wyróżniony komponent emocjonalny badanych postaw jest znacznie silniejszy w odniesieniu do Ruchu Palikota.

3. Wśród sympatyków PJN silną agendą socjalizacji politycznej jest rodzina oraz (na co wskazuje uwarunkowanie sympatii wobec lidera tego ugrupowania) przywiązanie do wartości patriotycznych i nacjonalistycznych.

4. Kształtowanie sympatii wobec Ruchu Palikota oraz jego lidera uwarunkowane jest odrzuceniem tradycyjnej agendy socjalizujących, jaką jest Kościół katolicki. Wydaje się, że tę właśnie grupę wyborców można scharakteryzować jako taką, wśród której obserwujemy kryzys tradycyjnych wartości rozumianych jako przywiązanie do tradycji katolickiej oraz rozumienia patriotyzmu w kategoriach wartości nacjonalistycznych. Wskazanie partnera jako znaczącego w kształtowaniu własnych sympatii i poglądów politycznych może świadczyć o braku zaufania do starszego pokolenia i podważaniu tradycyjnych autorytetów. W dynamicznie zmieniającym się, ponowoczesnym społeczeństwie to właśnie rówieśnicy mogą być spostrzegani jako tacy, którzy są w stanie odpowiedzieć na wyzwania współczesności i to ich poglądy mogą być postrzegane jako bardziej adekwatne i znaczące.

Reasumując, z przeprowadzonych badań wynika, że sympatie wobec badanych ugrupowań deklarują znacznie różniące się między sobą grupy studentów. Pozytywne emocje wobec Janusza Palikota i jego partii odczuwają studenci kontestujący tradycyjne instytucje socjalizujące - szczególnie organizację religijną - oraz sprzeciwiający się rozumieniu patriotyzmu w kategoriach nacjonalistycznych. Warto podkreślić, że ich postawy polityczne zbudowane są na negatywnych emocjach wobec PiSu i jego lidera. Studenci sympatyzujący z PJN i Pawłem Kowalem swoje poglądy polityczne kształtują poprzez wpływy socjalizacyjne rodziny pochodzenia, mający poglądy nacjonalistyczne.

\section{Literatura}

Aronson E., Wilson T. D., Akert R. M. (1997). Psychologia społeczna - serce i umyst. Poznań Delli Caprini M. (2000). Youth, Civic Engagement, and the New Informational Environment. „Political Communication”, n. 17, s. 341-349 
Franklin M. (1996). Electoral Participation. (W:) Comparing Democracies. Election and Voting in Global Perpective. Red. L. LeDuc, R.G. Nemi, P. Norris. New Delhi, London

Garlicki J., Bogomilski N. (2004). Kultura polityczna w społeczeństwie demokratycznym. Warszawa

Jakubowski W., Marciniak E.M., Załęski P. (2008). Socjalizacja polityczna młodego pokolenia Polaków. Warszawa

Mandrosz J. (2002). Czynniki ograniczające racjonalność poglądów i zachowań politycznych. (W:) Podstawy psychologii politycznej. Red. K. Skarżyńska. Poznań

Myers D.G. (2003). Psychologia społeczna. Poznań

Pawełczyk P., Churska-Nowak K., Jankowiak B. (2012). Struktura i uwarunkowania emocjonalnego komponentu postaw politycznych studentów. „Przegląd Politologiczny”, Rok XVII, Nr 4

Pawełczyk P., Jankowiak B. (2013). Cechy wizerunku politycznego a emocje w głosowaniu na Bronisława Komorowskiego i Jarosława Kaczyńskiego w wyborach prezydenckich w 2010 roku. Raport z badań postaw politycznych studentów. „Przegląd Politologiczny” Rok XVII, Nr 2

Smith A. (1999). The Effects of Investment in the Social Capital in Youth on Political and Civic Behavior in Young Adulthood. „Political Psychology” no. 20, s. 553-580.

Uslaner E. (1998). Social Capital, Television and He Mean Word: Trust, Optimism, and Civil Participation, „Political Psychology”, no. 19, s. 441-467

Wattenberg M.P. (1987). The Hollow Realignment: Partisan Change in a Candidate-Centered Era. „Public Opinion Quarterly” 51

http://www.polityka.pl/kraj/1514288,1,pjn-partia-sad-zarejestrowal-statut.read?backTo=http://www.polityka.pl/kraj/analizy/1515882,1,jak-nie-powstaje-pjn.read (dostęp: 15.03. 2013)

http://wiadomosci.dziennik.pl/polityka/artykuly/303891,palikot-odchodzi-z-po-z-sejmu-izaklada-partie.html (dostęp: 15.03.2013)

http://polska.newsweek.pl/palikot-twoj-ruch-to-nowa-nazwa-parti-na-newsweek-pl,artykuly,271980,1.html (dostęp: 09.11.2013)

\section{Conditioning of Appreciation Towards PJN and RP in Studies of Students' Political Attitudes}

\section{Summary}

The aim of this work is to analyze the results of the survey concerning the structures and conditioning of students' political attitudes. The attitude is a general, positive or negative stance which is reflected in believes, emotions and intentional behaviours. Three-part definition says, that it constitutes components: emotional, cognitional and behavioural.

Cognitional component, which concerns thoughts and believes about the issue of attitude (including cases of political attitudes about the politics, political system as totality, political institutions, political parties, their candidates and platforms);

Affective component (emotional), which involves emotional reactions directing towards the issue of attitude which including cases of politics, political system, political institutions and politicians; 
Behavioural component, which is associated with acting of individuals as it constitutes the noticeable behaviour towards the issue of attitude (i.e. political activity: conventional and unconventional, political participation, voting behaviour).

The analysis concerns the emotional component of political attitudes as there are many studies which improve the significant role of emotions towards the politicians which have an impact on voting. The factors which create the sympathy towards two political parties, Palikot's Movement (presently Your Movement) and Poland Comes First and their leaders, were shown.

The assessment of sympathy towards the parties was made in order to find out if it is not related with the political organizations from which the leaders come (Civic Platform and Law and Justice). The issue of emotions was also analyzed since they are important elements of the attitudes, as well as they form them. The studies associated with the political attitudes improve that emotions towards the candidates have an impact on the voting process. Electors often have preconception feelings towards the candidates when they don't know anything about their platforms. On the basis of survey we can a few conclusions.

There are distinctive differences between the recognition of Palikot's Movement and Poland Comes First's leaders. Janusz Palikot is known by the vast majority of students $(96,68 \%)$ and Paweł Kowal is known by merely one-third of people being tested $(34,21 \%)$. It shows the efficiency of conducted campaign in the group of young and educated voters.

Because of recognition of the leaders, it is not surprising that the emphasized emotional component of the examined attitudes is much more stronger to Palikot's Movement.

Among the supporters of Poland Comes First, the powerful socializing agenda is family and attachment to patriotic and nationalist values (the conditioning of sympathy towards the leader stresses it).

Forming of appreciation towards Palikot's Movement and its leader is determined by rejecting of traditional socializing agenda like Catholic Church. It seems that the mentioned group of voters can be characterized as the group in which the crisis of traditional values can be observed, like attachment to Catholic traditions and the essence of patriotism in context of national value.

Presenting the partner as significant in forming the appreciation and political views, may show the lack of trust towards the elder generation and challenging the traditional authorities.

In dynamically changing postmodern society, peers can be perceived as people who can manage the challenges of contemporary times and thus their views can be recognized as more adequate and meaningful.

To sum up, the studies improve that appreciation of examined political parties is declared by disparate groups of students. Positive emotions to Janusz Palikot and his party are observed among the students who question traditional socializing institutions, particularly religious organization, and object the essence of patriotism in context of national value. It's worth mentioning that their political attitudes are formed on negative emotions towards Law and Justice and its leader. Students who support Poland Comes First and Paweł Kowal form their views through the socializing influences of social background, having the nationalistic views. 